\title{
Research on Consistent Pattern of Development of the Educators' Ability to Self-Improvement
}

\author{
Boris Fishman $^{1}$, Bogdana Kuzmina ${ }^{1}$, Olga Fokina ${ }^{1}$, Miron Fishbein ${ }^{1}$, Natalya Moskvina ${ }^{2}$, Svetlana Mashovetz ${ }^{2}$, \\ Raisa Serezhnikova ${ }^{3}$ \\ ${ }^{1}$ Sholom-Aleichem Priamursky State University, Jewish autonomous region, Birobidzhan, Russia \\ ${ }^{2}$ Far Eastern Federal University, Primorskiy Krai (Territory), Vladivostok, Russia \\ ${ }^{3}$ Kaluga Slate University named after K.E. Tsiolkovski, Kaluga region, Kaluga, Russia \\ Correspondence: Boris Fishman, Sholom-Aleichem Priamursky State University, Jewish autonomous region, \\ Birobidzhan, Shirokaja st., 70-a, 679015, Russia. Tel: 7-924-640-4126. E-mail: bef942@mail.ru
}

Received: March 12, 2017

doi:10.5539/ass.v13n9p26

\author{
Accepted: July 9, $2017 \quad$ Online Published: August 25, 2017 \\ URL: https://doi.org/10.5539/ass.v13n9p26
}

\begin{abstract}
The educators' ability to self-improvement is considered in the article by means of a special system. It can be represented as a three-level hierarchical model with fuzzy structural relationships. The intermediate level of this model contains components that enable the formation and development of the object of the upper level (educators' ability to self-improvement): 1) motivational-valuable component; 2) the emotional-volitional component; 3) reflective-evaluative component; 4) cognitive component; 5) organizing component. The lower level of the model contains indicators. They make it possible to evaluate the degree of the selected components' formation and the stage of the development of the investigated ability as a whole. Each state of the educators' ability to self-improvement is characterized by a tuple. The stage reached by the relevant components is the element of this tuple. According to self-assessments received from 214 lecturers and teachers, the most common states were defined. It has allowed to form a sequence of such states. The transitions between them describe the patterns of development of the educators' ability to self-improvement. The described technique allows us to characterize the development of this ability not only among educators, but also among professional managers, doctors, engineers in the field of electrical engineering and electronics, and others.
\end{abstract}

Keywords: the educators' ability to self-improvement, a three-level hierarchical model, the state of the educators' ability to self-improvement, transitions between states, the patterns of development of the educators' ability to self-improvement

\section{Introduction}

It is well known that modern education is facing some serious challenges. Students' motivation for learning is weak. The relationship between the study of social experience and the students' formation of their own experience is not optimal. It has become disreputable to be a highly educated person with high moral values. The renewal rate of the content that is essential towards a proper education is insufficient.

The transition to a knowledge society requires a change in orientation of the educational process. It should not be dominated by a paradigm aimed at the assimilation of ready-made knowledge. Nowadays the main paradigm should be anthropic and focus on the cultivation of the human in a person. It is necessary to create conditions for the formation of cognitive strategies of self-learning and self-education among all participants in educational activities. The ability to obtain, understand, comprehend the information and put it into practice should be formed. The teachers and lecturers capable of self-development and performing their work creatively are required to resolve these problems successfully (Steele \& Zhang, 2016).

The task of training educators cannot be properly completed without the assessment of these abilities. The aim of this research is to design a method focused on the fulfillment of assessment of teachers' and lecturers' ability to self-improvement. These methodical tools will create a basis to compare the levels of formation of the abovementioned abilities among different educators, as well as the teachers and lecturers who work in different regions (in different countries). It will be possible to evaluate the effectiveness of teachers' and lecturers' training and retraining programs, as well as identify and characterize the socio-cultural factors that contribute or impede 
the process of self-improvement.

\section{Model of the educators' ability to self-improvement}

Today the ability to self-improvement is an integral quality in a person. It contributes to the successful teachers' and lecturers' professional activity. This ability means the formation, development and activation of the relevant qualities of the educators' personality (purposefulness, persistence, self-organization, etc.). It is a consequence of the unity of their professional and personal self-improvement. The intention to develop, learn new things and become more competent, better, more interesting for pupils, students and colleagues is included in the studied ability (URL: http://www.iisd.org/pdf/balatonreport.pdf (1999); Fishman, Merdeeva \& Fokina, 2016).

According to the systems approach the mentioned ability has the following principal features:

- Level of formation of ability to self-improvement among teachers and lecturers is determined more often through the qualitative variables

- The scales that are used to measure and evaluate various characteristics of such ability are polytypic

- The structure of mutual relationships between components of this ability is multi-layered and hierarchical

- There are the semantic intersections between components of educators' ability to self- improvement

The educators' ability to self-improvement is a complicated object in which a person takes an active role. The nature of these objects cannot be presented effectively through a model with a clear structure (Zadeh, 1975a; Zadeh, 1975b; Zadeh, 1975c). Therefore, approximate approaches and techniques with the use of linguistic variables should be applied to measure and assess the level of their development. In this way the description of a peculiar reflection of the world and himself by the person can be provided.

Thus, for diagnostic purposes the teachers' ability to self-improvement may be presented by means of the hierarchical model (see Fig. 1). This is a three-level cognitive model with fuzzy (vague) structural semantics (Fishman, Trukhina \& Merdeeva, 2011; Fishman, Merdeeva \& Fokina, 2016 and others).

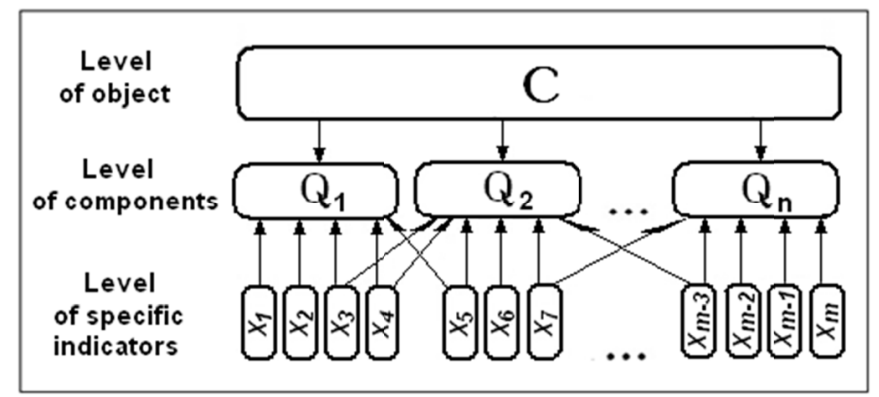

Figure 1. The Scheme of the Three-Level Model. The conceptual structure of the investigated object is represented here. The fuzziness of relations between indicators and the examined components is registered

The upper level of this model is presented by the examined object - the educators' ability to self-improvement. At this level the object is characterized systemically, holistically. It is described by a set of qualities that define it and distinguish it from the environment.

The content of the intermediate level includes the complex of components that provide formation, development and activation of mental conditions and qualities of teachers' personalities. Such conditions and qualities contribute to the successful performance of educators' professional activity (Slusareva, 2010). Having studied numerous researches (see Abakumova, 2013; Melyohina, 2008 and other) the following array of the five basic structural components of teachers' and lecturers' ability to self-improvement was selected:

- Motivational-valuable component $Q_{1}$ - interest in activity, need for successful execution of the given tasks, stability of leading professional values and interests, eagerness for the professional excellence and self-improvement;

- Emotional-volitional component $\mathrm{Q}_{2}$ - the system of emotional and volitional qualities of the individual, providing him with the ability to manage actions, emotional stability in understanding and acceptance of problems, activity, orientation, perseverance, persistence etc.;

- Reflective-evaluative component $Q_{3}$ - the skill to recognize any problems and difficulties, the ability to understand the reasons for the success or failure, readiness for self-reflection, self-criticism. Maturity perceptions of the personality and professional activity, the proficiency to estimate opportunities, etc.; 
- Cognitive component $\mathrm{Q}_{4}-$ knowledge necessary for realization of activity, problem solving skills, possession of relevant social experience and the ability to use it in professional activity;

- Organizing component $\mathrm{Q}_{5}$ - awareness of necessity and importance of self-management and self-organization, ability to plan activities, possession of techniques to self-control and self-manage, skill to renew the system of professional activity.

The lower level of the model contains specific indicators. They make it possible to evaluate the degree of formation of the selected components and considered ability as a whole. Each indicator is available for a monitoring and direct evaluation (measurement).

\section{Method}

Method development was held in three stages. First of all a specific set of indicators was determined. In this case the following requirements were used:

- Used indicators $x_{r}$, whose meaning can be understood clearly. All of them should be accurately observed and recorded

- Feature $\tau$ is measured (estimated) for each indicator $x_{r}$. This feature is the frequency of occurrence that is displayed in the values of the ordinal scale

- The wording of each indicator $x_{r}$ should give the opportunity to execute the interpretation of the meaning of the used values. One of the values must be determined as normal

- The relationships between the indicators and the conceptual model's components do not necessarily have to be strict. Every indicator $x_{r}$ may characterize several components $Q_{j}$ and therefore it should be described by the corresponding membership function $\mu_{\mathrm{j}}\left(\mathrm{x}_{\mathrm{r}}\right)$.

45 indicators have been used in the conceptual model of teachers' and lecturers' ability to self-improvement. The values of the membership function $\mu_{\mathrm{j}}\left(\mathrm{x}_{\mathrm{r}}\right)$. for each indicator $\mathrm{x}_{\mathrm{r}}$ have been assessed by experts. So, for example, to evaluate the organizing component $Q_{5}$ the following indicators are used (Note 1 ):

$-x_{1}-$ Carries out the plan of the work $\left(\mu_{5}\left(x_{1}\right)=1\right)$

$-x_{2}$ - Uses office equipment and the databases available through computer information $\boldsymbol{\mu}_{\mathbf{5}}\left(x_{2}\right)=1$ )

$-x_{3}-$ Knows the methods of self-improvement $\left(\mu_{5}\left(x_{3}\right)=1\right)$

$-x_{4}$ - Manages time $\left(\boldsymbol{\mu}_{\mathbf{5}}\left(x_{4}\right)=0,6\right)$

$-x_{5}-$ Applies techniques of self-organization $\left(\boldsymbol{\mu}_{\mathbf{5}}\left(x_{5}\right)=0,6\right)$

$-x_{6}-$ Aware of need and the importance of self-organization and self-management $\left(\mu_{5}\left(x_{6}\right)=0,6\right)$

$-x_{7}-$ Focuses on the sources necessary for the development of a personal and professional culture $\left(\boldsymbol{\mu}_{5}\left(x_{7}\right)=0,6\right)$

$-x_{8}-$ Reconstructs the system of professional work $\left(\boldsymbol{\mu}_{\mathbf{5}}\left(x_{8}\right)=0,4\right)$

$-x_{9}-$ Works productively with literature $\left(\boldsymbol{\mu}_{\mathbf{5}}\left(x_{9}\right)=0,4\right)$

Note that most of the indicators belong to more than one component (so, in the example above only three first indicators belong to the organizing component and the rest - to the two or three other components). Thus, the total amount of the selected 45 indicators includes:

- an aggregate of 25 indicators, which characterize the motivational-value component;

- an aggregate of 24 indicators, which characterize the emotional-volitional component;

- an aggregate of 23 indicators, which characterize the reflective-evaluative component;

- an aggregate of 33 indicators, which characterize the cognitive component;

- an aggregate of 22 indicators, which characterize the organizing component (Fishman, Merdeeva \& Fokina, 2016).

At the second stage the formalized representation of any position of educators' ability to self-improvement is introduced. The following assumptions were used:

- Intensity index of every $n$-th indicator characterizes the level of development of the $j$-th component $\mathrm{Q}_{j}$ in accordance with the membership function $\boldsymbol{\mu}_{\boldsymbol{j}}\left(x_{r}\right)$

- For an assessment of the level of each component's development the correct procedures for the aggregation of the indicator's intensity can be designed 
- The level of educator's ability to self-improvement is characterized by a set of estimates of the level of all components' development; they are represented as a tuple, i.e. are not aggregated (Fishman \& Fokina, - 2014).

In fact, the number of components determines the number of degrees of freedom in the space of the described object (the educators' ability to self-improvement). Thus it defines the maximum possible specification of this description.

Let us consider a set of $N$ educators. The level of ability to self-improvement is evaluated for each of them. A set of assessments that characterize the levels of $k$ components of $n$-th educator can be written as a tuple (Note 2) $\hat{e}_{n}=\left\{\hat{P}_{1}, \hat{P}_{2}, \ldots \hat{P}_{k}\right\}$. Here $\hat{P}_{i}$ is the rating of the degree achieved by the $i$-th component. This tuple represents the assessment of the ability to self-improvement generally achieved by the $n$-th educator. In fact, this tuple is the estimated model that symbolically displays this position.

If $l$ states of development can be determined for each component, then the number of different states of the process depends on the value of $l$. It is clear that there are only $l^{k}$ distinguishable states of process.

At the third stage the cognitive map that visually displays an idea about the investigated process is formed. On such map-viewing a concrete location of all $l^{k}$ distinguishable states of process and allowable transitions between them are specified. Thereby the whole range of potential possibilities of development of this process is represented.

When constructing a map-viewing, the following rules are used:

- Map-viewing has the form of the graph, whose vertices form the distinguishable states of the process

- Each distinguishable state, which is described by a certain tuple, is considered as the relevant vertex of the graph

- Two distinguishable states are considered as neighboring if their tuples differ in the index of the level of any one development component, and moreover the value of this index differs per 1

- To the right on the graph neighboring vertices are situated. At each vertex a tuple has a larger value of the discrepant indicator

- An increase of index of level for only one of the components takes place for all allowable transitions from any vertices to the neighboring one. Indexes of the level for other components remain unchanged. Such transitions are represented as directed arcs connecting the adjacent vertices.

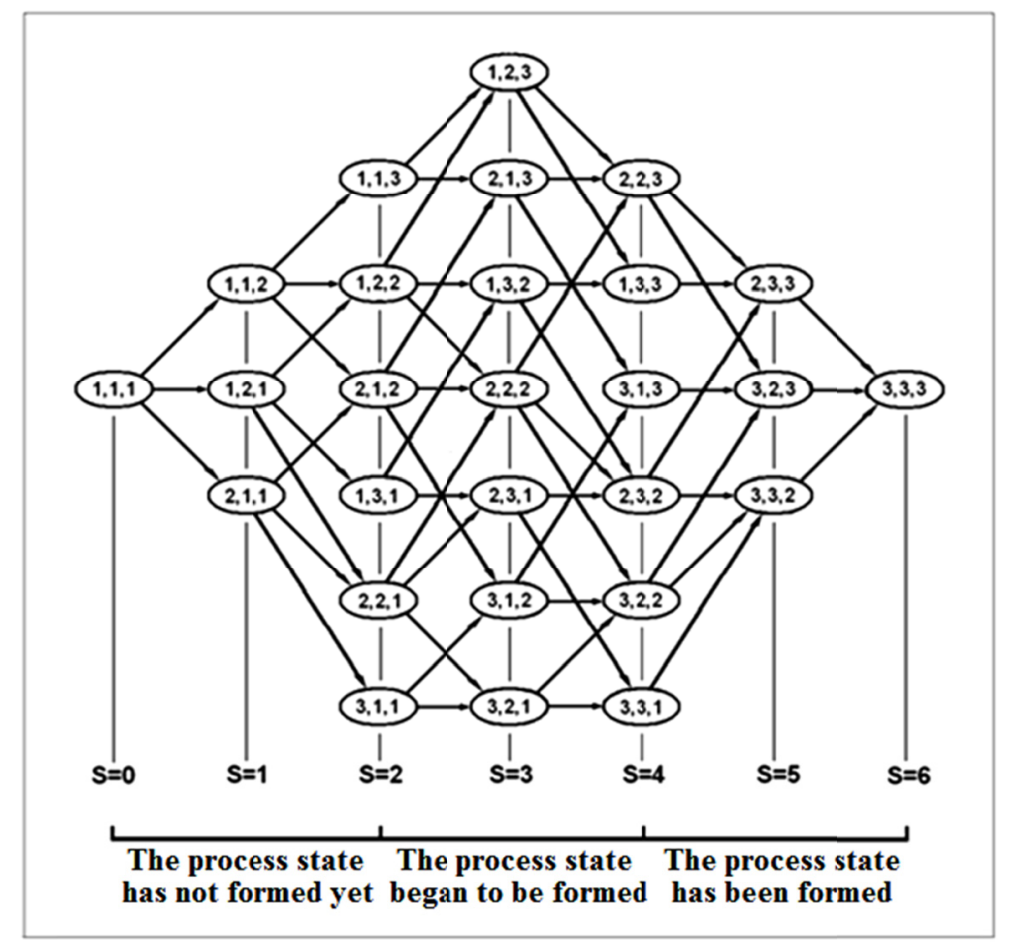

Figure 2. The graph of the set of possible transitions in the development of the process, which is described by three components 
As an illustration, Figure 2 is the graph of the possible trajectories of the object development which is described by the three components.

Each component is evaluated by one of three possible levels of the scale, describing the three stages of the development. Vertices of the graph (distinguishable states) are represented by ellipses, in which the corresponding tuples are recorded. Vertical lines pass through the states of the process which are formed in $S$ steps. In this case $S=0$ - the initial state in which the process is hidden and its indicators point to the lower level of development of all components. $S=6-$ the final state in which the process is the most developed.

On fig. 2 the possible transitions of the process are presented. Such process has a simpler structure than the structure of the process of educators' self-improvement. Since this process is described by five components, its map-viewing contains $3^{5}=243$ states. However, the empirical data indicates that the majority of these states are unoccupied. That is why a map-path of the investigated process is more informative than a map-viewing.

\section{Results}

A random sample of teachers and educators was formed to assess their ability to self-improvement. It included 214 teachers and lecturers from five regions of the Far East of Russia (96 lecturers and 118 teachers). Each of the participants evaluated their activities using 45 offered indicators. Verification of these estimates was performed on the basis of the analysis of opinions and statements from colleagues and supervisors.

At first it was determined whether the factor of where the teacher worked (at a school or at a university) was significant or not. The use of $\chi^{2}$ test showed that the distributions of estimates of 39 indicators in a group of lecturers (96 people) and in a group of teachers (118 people) were not significantly different. Statistically significant differences of distributions were found only for 6 indicators. Thus, with a confidence probability of $86,7 \%$ we have made a decision on the possibility to unite a group of lecturers and a group of teachers. All the results that characterize the dynamics of teachers' ability to self-improvement have been obtained on the basis of the empirical data of the pooled sample.

After analysis of self-assessments the different development states of the investigated ability were considered. The map-path of this process is shown in Figure 3.

\section{Steps of the process development}

Step 1 Step 2 Step 3 Step 4 Step 5 Step 6 Step 7 Step 8 Step 9 Step 10

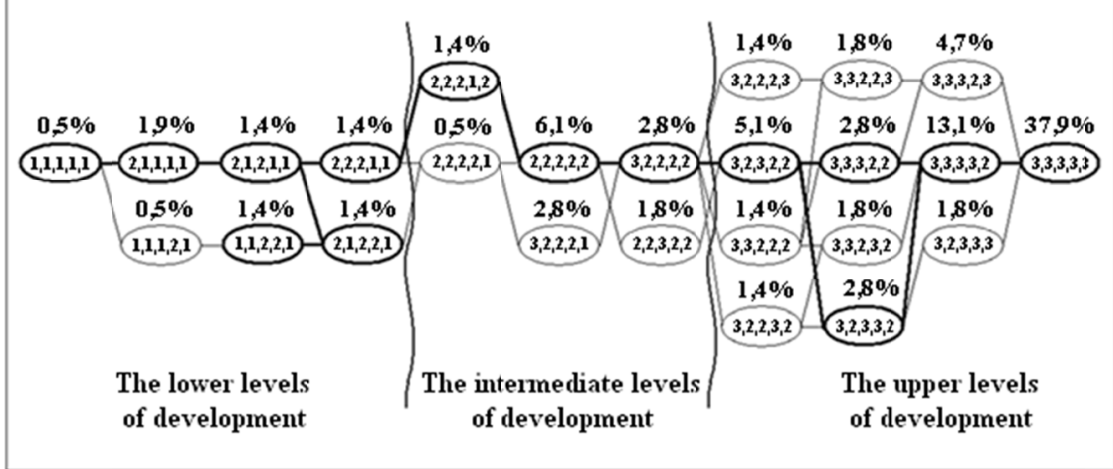

Figure 3. The map-path of the ability to self-improvement of teachers and lecturers.

The ellipses contain tuples that represent the state of this process (Note 3). The relative quantities of teachers' and lecturers' in the corresponding states are written above the ellipses. Bold ellipses denote the states with the highest relative quantities at each step, and the thick lines connect these states.

The initial state is represented by the tuple $(1,1,1,1,1)$, in which all components are not developed and are at a minimum level of 1 .

After the 1st step, one of the components moves on the 2 nd level. There are 2 of these states $(2,1,1,1,1)$ and $(1,1,1,2,1)$. In the first of them, the 1st component («motivational-valuable component») moved on the 2 nd level, and in the second - the 4th component («the cognitive component») moved on the 2 nd level. According to empirical data the state $(2,1,1,1,1)$ occurs 4 times more often than the state $(1,1,1,2,1)$.

After the 2 nd step 2 components already reach the 2 nd level. There are 2 of these states: $(2,1,2,1,1)$ and $(1,1,2,2,1)$. Transition into these states is associated with the development of the $3 \mathrm{~d}$ component 
(«reflective-evaluative component») to a 2 nd level. According to empirical data both states $(2,1,2,1,1)$ and $(1,1,2,2,1)$ occur with the same frequency.

Similarly we can consider the further steps.

The analysis of states that have been identified on the basis of empirical data, points to the following empirical regularities of development of teachers' and lecturers' ability to self-improvement:

1. Development of teachers' and lecturers' ability to self-improvement is not a well-defined linear process. This process has a non-linear probabilistic nature. Each transition to a higher level is carried out step by step, without a "jump" through any level. The different sequences of states, reflecting the development of the components of this ability, may be realized.

2. The following order of the most probable development of various components is implemented. The state where the «motivational-valuable component» is located on the next level is formed first of all. After that the «reflective-evaluative component» is detected on a higher level. Next, the «emotional-volitional component» is enhanced to a new level. Then, the «cognitive component» is developed up to the following level. Finally, the «organizing component» completes the cycle of transitions to the next level.

\section{Discussions}

Identification of the most likely order of the components' development of the educators' ability to self-improvement opens a new opportunity to study this process. It is known that the traditional method of studying the dynamics of such process can be realized only on the basis of prolonged observation. However, it is clear that its duration cannot be less than the time of the investigated process development.

Now it is possible to form a mixed research strategy and significantly shorten the duration of prolonged observation. It is not necessarily to observe the dynamics of the whole process entirely, because this dynamic is represented by the most likely development path. It is possible to explore only those educators, whose process of self-improvement is in certain states, and to observe them only while the transition out from these states will take place.

In addition, the integration of the results of one-time observations together with datasets of prolonged observations makes it possible to remove the requirement of a single sample set of observations objects. It is sufficient to fulfill the following conditions:

1) The representativeness of the sample which is used in the initial empirical model based on the results of one-time observations;

2) The representativeness of the samples for prolonged observation, which are initially «tied» to the various achievable states

In this case there is no requirement of the same composition of the used samples.

\section{Conclusion}

The development of this area allows to receive new results and to offer new research tasks. Let us formulate some of them.

Task 1 «The study of the reversible segments of trajectory development». This problem can be solved on the basis of a mixed research strategy. Examining the participants of the process of self-improvement, which are in a particular state, it is possible to determine the ratio of the number of those who go to the next state, and those who return to the previous one. With the necessary volume of the sample the probability of a reverse development process can be determined and the factors contributing to this development can be identified. Sequential study of the direct and reverse options of the development for each state will allow determination of the reversible segments of trajectory development of this process.

Task 2 «The possibility to manage the selected process' development». It is clear that acting factors have specific efficiency of influence on the various stages of the selected process development. Hence, it is possible to identify the main factors that accelerate or hamper the process of development. As a result, the conditions that provide the necessary characteristic of the process at every stage of its development can be identified and experimentally verified.

Task 3 «The individualization of the educational process in additional teacher retraining». As a result of the diagnosis of the current state of the teachers' ability to self-improvement the zone of their proximal development can be identified. Therefore, it is possible to form a group of participants' training courses or professional training, which will combine teachers and lecturers with similar zones of proximal development. For such groups, 
special education programs targeted at the specific needs of proximal development can be designed. This can significantly increase the effectiveness of additional pedagogical education.

Task 4 « Investigation of other professionals' ability to self-improvement». Nowadays the ability to self-improvement has become an essential quality of the competitive specialist. The described technique allows us to characterize the development of this ability among a variety of workers, such as professional managers, lawyers, doctors, engineers and others. It will be possible to reveal the general patterns of this development and the influence of professional specifics on its features.

\section{References}

Abakumova, E. B. (2013). Self-educational activity of the modern teacher. Problems and prospects of development of education: Materials of III International. Scientific. Conf. (Perm, January 2013). Perm: Mercury, 2013. Pp. 133-135.

Fishman, B. E., \& Fokina, O. A. (2014). The ability of educators to develop their own professional culture: a methodical base of diagnosis. Modern problems of science and education, 6. https://www.science-education.ru/120-16071.

Fishman, B. E., Merdeeva, B. S., \& Fokina, O. A. (2016). Operationalizing assess the state of weakly formalized object: monograph. Birobidzhan: Publishing center of Sholom-Aleichem Priamursky State University.

Fishman, B. E., Trukhina, O. A., \& Merdeeva, B. S. (2011). Modeling the processes of educators' self-improvement in the area of meanings «strategic goal appointment - competence». Modern problems of science and education, 3. https://www.science-education.ru/97-4708.

Indicators for sustainable development: theory, method, applications. A report to the balaton group / h. Bossel Manitoba: International institute for sustainable development. (1999). http://www.iisd.org/pdf/balatonreport.pdf.

Melyohina, E. A. (2008). Role of continuous formation in professional development of teachers. Pedagogical Education and Science, 12, 20-25.

Slusareva, E. S. (2010). The psychological readiness of special psychologist to psycho correctional work with children: monograph. Stavropol: Publishing house of SSPI.

Steele, D., \& Zhang, R. (2016). Enhancement of Teacher Training: Key to Improvement of English Education in Japan. Procedia - Social and Behavioral Sciences, 217, 16-25. https://doi.org/10.1016/j.sbspro.2016.02.007

Zadeh, L. A. (1975a). The Concept of a Linguistic Variable and its Application to Approximate Reasoning. I. Information Sciences, 8(3), 199-249. https://doi.org/10.1016/0020-0255(75)90036-5

Zadeh, L. A. (1975b). The Concept of a Linguistic Variable and its Application to Approximate Reasoning. II. Information Sciences, 8(4), 301-357. https://doi.org/10.1016/0020-0255(75)90046-8

Zadeh, L. A. (1975c). The Concept of a Linguistic Variable and its Application to Approximate Reasoning. III. Information Sciences, 9(1), 43-80. https://doi.org/10.1016/0020-0255(75)90017-1

\section{Notes}

Note 1. In parentheses the expert assessments of values of the membership function of each indicator for this component are written.

Note 2. A tuple in mathematics and in computer sciences - an ordered set of $n$ elements (components), where $n$ is any integer. A set of elements of tuple has a certain order and each component has a fixed position in the set.

Note 3. In all of these tuples the first element characterizes the level of development of motivational-valuable component, the second - level of development of emotional-volitional component, the third - level of development of reflective-evaluative component, the fourth - level of development of the cognitive component, the fifth - level of development of the organizing component.

\section{Copyrights}

Copyright for this article is retained by the author(s), with first publication rights granted to the journal.

This is an open-access article distributed under the terms and conditions of the Creative Commons Attribution license (http://creativecommons.org/licenses/by/4.0/). 